\title{
Geostatistical approach to the estimation of the uncertainty and spatial variability of soil settlements in the region of Kenitra (Morocco)
}

\author{
Mohamed Ben Haddou ${ }^{1}$, Ali Essahlaoui ${ }^{1}$, Mohamed Boujlal ${ }^{2}$ \\ ${ }^{1}$ Water Sciences and Environmental Engineering $»$ team of research, geo-engineering and environment \\ laboratory, Geology Department, Faculty of Sciences, Meknes; PO Box 11201 Zitoune - 50000 Meknes - \\ Morocco, \\ ${ }^{2}$ National Office for Railways (ONCF), 8 bis, Street of Abderrahmane El Chafiki-Rabat Agdal - Morocco.
}

\begin{abstract}
This article presents a case of application of geostatistical methods in geotechnical engineering: There is a railway platform, going to be built on compressible soils which presents important settlement. Geotechnical data were analyzed by a geostatistical approach using GIS software to characterize the spatial variability of the thickness of the compressible soils and their deformation Module.

Then these data were crossed with settlement calculations by oedometer method to estimate the distribution of soil compaction on the entire site.
\end{abstract}

Key words: Morocco, Kenitra, geotechnical studies, settlement, geostatistics, kriging.

\section{INTRODUCTION}

Soil, whatever their nature, are deformed under the effect of loads applied to them with highly variable amplitudes. And it is this degree of deformability that allows classifying soils into highly compressible soils (soils that may undergo significant settlements) and slightly compressible soils. A calculation of the settlements is then necessary to ensure that they are acceptable for structures to be built.

This paper presents a geostatistical approach to estimate the settlements of compressible soils located below a platform for a High-Speed Line (HSL).

First, we present an approach for estimating an elastic Module of compressible soils by using the results of odometer tests performed on samples taken by core drilling.

Then these values are used to calculate soil compaction, based on the compressibility characteristics obtained from odometer tests. The settlement values obtained depend on the geology of the site; lithological variability is therefore taken into account.

A geostatistical treatment of these values allows finally to establish a map showing the spatial distribution of the settlements across the study site.

\section{PRESENTATION OF THE SITE OF STUDY}

The morphological and geological context:

The area of study is bounded by the hills of Lalla Zohra to the north, by Maamora plain to the south, by the hills of Bou Draa and Bel Ksiri to the east and by the Atlantic Ocean to the west. A large closed basin, whose center is occupied by rivers of Sebou and Beht, is situated at less than 10 meters of altitude even if edges do not exceed a few hundred meters.

Towards the sea, the basin is also closed by the dune Sahel wide of 5 to $25 \mathrm{Km}$ and high of about 30 to 50 meters. The numerical model of the ground, introduced by the, shows well the dominance of low-lying lands. (Fig.1).

From a geomorphologic point of view, the zone of study crosses several geomorphologic sets: The sandy formations of Maamora in the bypass of the city of Kenitra, the Gharb plain with alluvial deposits of the Sebou river and the cord of coastal dunes beyond the plain of Sebou

The geological study constitutes a primordial and an essential stage for any geotechnical synthesis. Not only it allows to define well the lithology, the structure and the geological history of the region but it also allows to delimit the geographical spread of the different facies and their distribution modes.

On the whole, the Gharb basin, asymmetrical and hardly subsident since its formation in the middle of Miocene, knew in the course of its evolution several fluctuations of sea level linked to the neotectonic movements. The latter were translated in the coastal zone by faults and by a regular uprising of Meseta, resulting from an isostatic readjustment [1]; [2]; [3]; [4]; [4]; [5]; [6]; [7]; [8]. These variations are, in most cases, due to tectonic activity and to sedimentary provisions. The effect of the short-term sea level fluctuations, is added to the long-term tectonic movements. 


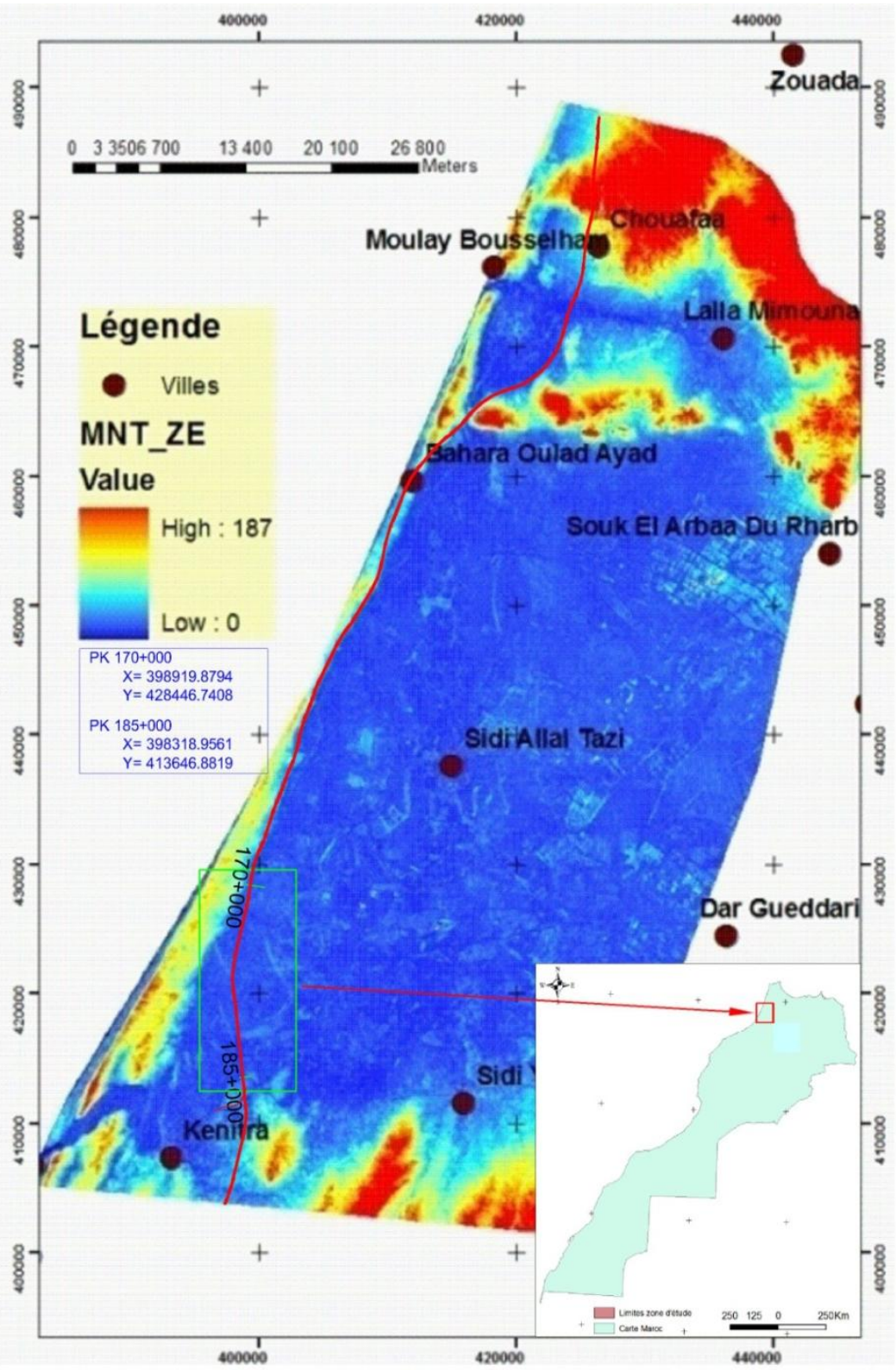

FIGURE.1. NUMERICAL TERRAIN MODEL AND LOCATION OF THE STUDY AREA

\section{II.1 Problematic}

Tanger-Kenitra line is a strategic segment nationally. It connects two cities experiencing a large population and economic growth in recent decades. This is why Morocco has chosen to perform a High-Speed rail Line (HSL) that connects the two cities. This line is part of an ambitious project developed in 2005 by ONCF and that aims to achieve $1,500 \mathrm{~km}$ of high-speed rail lines in less than two decades.

As it was reported earlier, the region is part of the Gharb plain known geologically by subsidence phenomena as well as the presence of settling soils. However, the High-Speed Line infrastructure is very sensitive to compaction phenomena. Therefore, the major problem is to estimate the settlements, the thickness of the compressible layer, and spatialization of the uncertainty of settlements across the study area.

\section{II.2 Geotechnical data used}

A geotechnical database assimilating all the available survey data was created. It enables statistical treatment of the different mechanical properties of soils. Also, necessary data for estimating settlements can be proposed in a rational way across the site. Table 1 below summarizes the average values obtained from odometer tests based on lithology regardless of the depth. The coefficients of variation show the variability of values. These averages give an idea on the compressibility and permit to estimate settlements across the site. 
TABLE.1: MEAN ODOMETER PROPERTIES

\begin{tabular}{|c|c|c|c|c|c|}
\hline & \multirow{2}{*}{$\begin{array}{l}\text { Number } \\
\text { of tests }\end{array}$} & \multicolumn{4}{|c|}{ mean/Coefficient Lithologies of variability } \\
\cline { 3 - 6 } & 35 & $\mathbf{0 , 2 6} / 48.79 \%$ & $\mathbf{0 , 0 7} / 43.45 \%$ & $\mathbf{0 , 7 7} / 30.79 \%$ & $\mathbf{1 5 0 , 5} / 51.14 \%$ \\
\hline Mud & 88 & $\mathbf{0 , 2 1} / 42.45 \%$ & $\mathbf{0 , 0 6} / 61.76 \%$ & $\mathbf{0 , 6 7} / 30.88 \%$ & $\mathbf{1 9 0 , 9} / 66.29 \%$ \\
\hline Clay & 25 & $\mathbf{0 , 1 5} / 40.46 \%$ & $\mathbf{0 , 0 4} / 54.29 \%$ & $\mathbf{0 , 6 4} / 24.94 \%$ & $\mathbf{1 9 0 , 6} / 66.73 \%$ \\
\hline Silty clay & 19 & $\mathbf{0 , 1 5} / 33.74 \%$ & $\mathbf{0 , 0 3} / 57.22 \%$ & $\mathbf{0 , 5 6} / 16.78 \%$ & $\mathbf{1 1 9 , 4} / 71.29 \%$ \\
\hline clayey silt & 17 & $\mathbf{0 , 1 3} / 63.45 \%$ & $\mathbf{0 , 0 2} / 65.60 \%$ & $\mathbf{0 , 5 2} / 29.08 \%$ & $\mathbf{9 2 , 1} / 63.51 \%$ \\
\hline Muddy sand & 17
\end{tabular}

With:

$(C c)$ : the compression index of soil

$(e 0)$ : the initial void ratio
$(C s)$ : the swelling index of soil

$(P c)$ : consolidation pressure

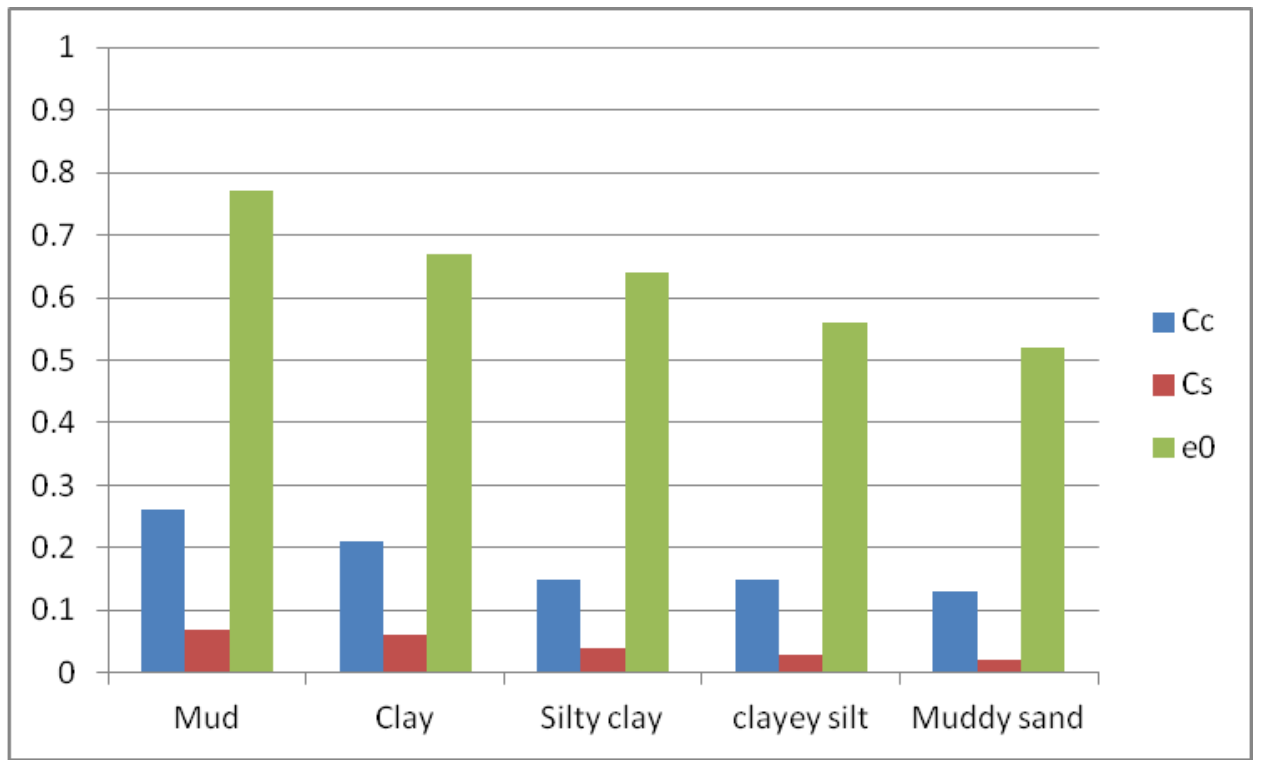

FIGURE .2: HISTOGRAM OF MEAN VALUES OF OEDOMETER TESTS

The Table above highlights the following points: 0.773 .

In the case of vase: parameters show high compressibility of the soil with a mean $\mathrm{Cc}$ of 0.263 and $\mathrm{e} 0$ of

In the case of clay, parameters show a relatively high compressibility of the soil with a mean $\mathrm{Cc}$ of 0.206 and $\mathrm{e} 0$ of 0.671 .

In the case of silty clay: parameters show an average compressibility of the soil with a Cc of 0.151 and a mean $\mathrm{e} 0$ of 0.637 which remains high. Consequently, these soils can compress significantly.

In the case of silts, parameters show a high mean compressibility of the soil with a mean Cc of 0.152 and a mean $\mathrm{e} 0$ of 0.558 .

In the case of silty sands and clean sands: the parameters show a low mean compressibility of the soil with a mean $\mathrm{Cc}$ of 0.13 and a mean $\mathrm{e} 0$ of 0.521 .

It was found that the soils are generally over-consolidated. A more detailed analysis shows that a significant part of the soil, without lithological distinction, is normally consolidated (Fig.3). The important variation of the over-consolidation ratio (OCR $\left.=\sigma^{\prime} p / \sigma^{\prime} v 0\right)$ depending on the depth necessitates to take it into account in order not to overestimate the settlements. The soils near the surface are not over-consolidated while the profound ones are so. 


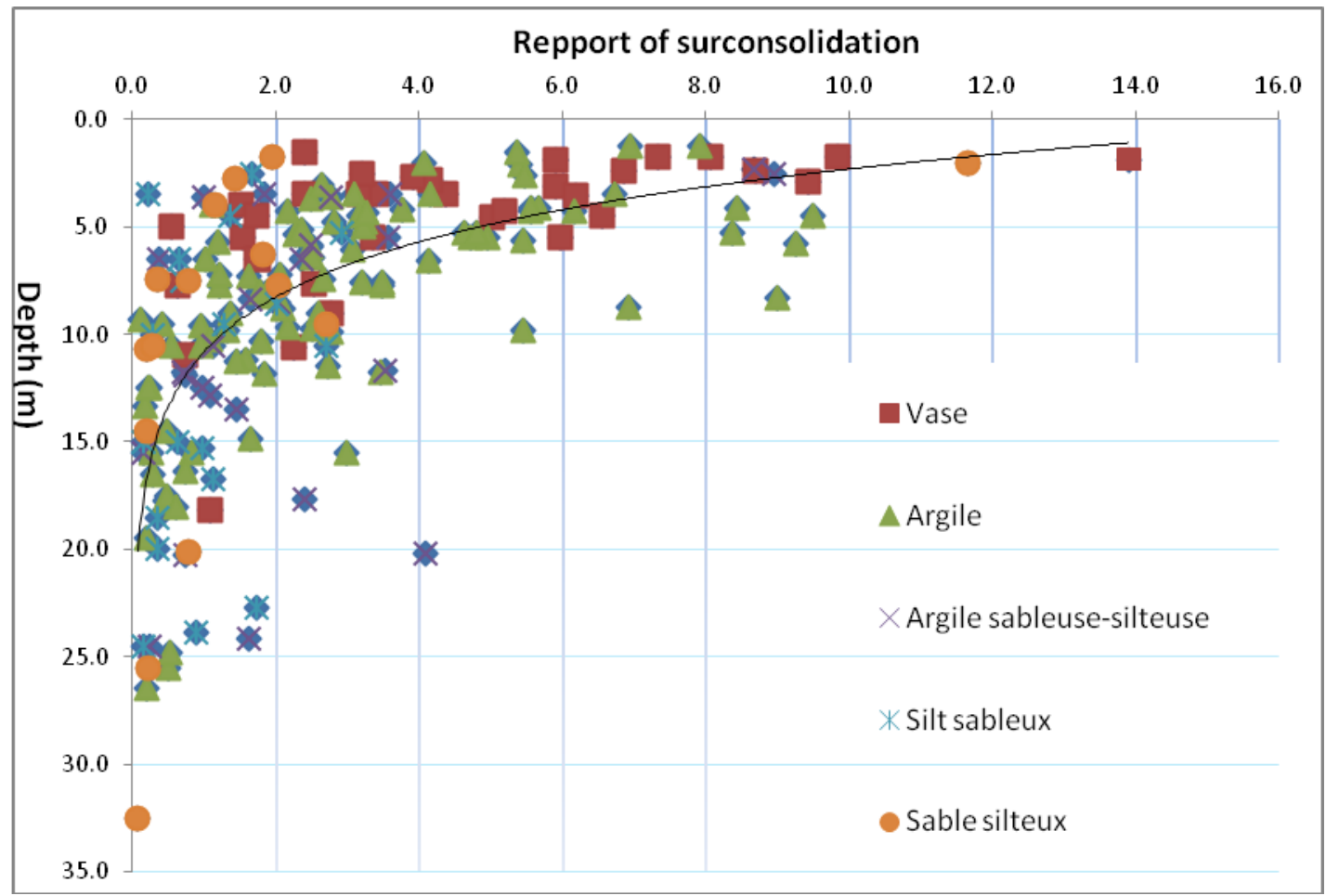

\section{FIGURE.3. OVERCONSOLIDATION STATE OF SOILS IN THE STUDY AREA}

\section{Estimation of an elastic Module of soil}

The odometer tests are commonly used to assess the settlements (total and differential), which occur if we implant an infrastructure on an untreated soil. To address these compaction problems, soil reinforcement is the most common practice. To enhance soil, a wide range of methods exist that can be classified into two categories: methods for improving mechanical properties (preloading, vertical drains, dynamic compaction ....) and methods of reinforcement inclusions (columns ballast piles, jet grouting ...).

Modeling of soil reinforcement by vertical inclusion requires the allocation of elastic Module to soils. However, their choice is often subjective and rarely justified. An approach is used below to access an elastic Module from odometer tests.

\section{The use of odometer data}

Odometer module is variable depending on the depth and the stress state of the sample. It is defined by:

$$
\mathrm{E}^{\prime} \text { oed }=\frac{\sigma_{x}}{\varepsilon z}[1]
$$

Where $\sigma \mathrm{z}$ is the applied stress during the test and $\varepsilon z$ the final relative settlement of the sample. The relative compaction is estimated by the formula [2], where $\mathrm{H}$ is the thickness of the compressible layer, $\Delta \mathrm{H}$ its settlement, and $\sigma^{\prime} \mathrm{vf}=+\sigma^{\prime} \mathrm{v} 0 \_\sigma^{\prime}$ the final effective vertical stress.

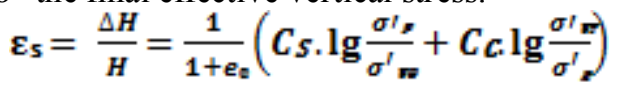

It is therefore possible to find the initial odometer Module from information provided by the tests in the study area. Odometer module is connected to the elastic Module E drained 'by equation [3]. Poisson's coefficient $v$ is taken equal to 0.3 .

$$
E^{\prime}{ }_{\text {oed }}=\frac{E v(1-v v)}{(1+v t)(1-2 v)} \approx \frac{E^{\prime}}{0.74} \quad[3]
$$

The water content is an easy physical parameter to measure (and inexpensive), there is, very often, a large number of values. Therefore, we can transform water contents of sorts to obtain the main parameters of compressibility, and as shown in Section 3.1., calculate elastic Module equivalent to the height of compressible soil.

Water content (W) is on our site, like most fine soils, empirically correlated with indices of compression (CC) and swelling (CS). The void ratio can be obtained by the relation $\mathrm{e}=\mathrm{W} \cdot \gamma \mathrm{S} / \gamma \mathrm{W}$. The initial vertical effective stress $\sigma^{\prime} v 0$ is estimated based on the depth and gravity $\gamma$ soil. The parameter of before consolidation effective stress $\sigma^{\prime} p$ is obtained from the over-consolidation ratio (Fig. 3). Once these estimates 
done, it is possible to calculate a relative deformation and thus find an odometer type module. This approach leads to the values of modules presented in Table 2 .

TABLE 2 . MEAN ODOMETERIC AND ELASTIC MODULES

\begin{tabular}{|c|c|c|c|c|}
\hline Lithologies & $\begin{array}{c}\text { Number } \\
\text { of values }\end{array}$ & E'oed $(\mathrm{kPa})^{\prime}$ & $\mathrm{E}^{\prime}(\mathrm{KPa})$ & $\mathrm{CV}(\%)$ \\
\hline Mud & 51 & 1955 & 1446 & 50 \\
\hline soft clay - silty & 63 & 2545 & 1883 & 63 \\
\hline Silteuseclay & 36 & 3584 & 2652 & 53 \\
\hline silty sand & 34 & 6108 & 4520 & 44 \\
\hline
\end{tabular}

These equivalent elastic modules have been integrated into a numerical calculation to estimate the settlements.

\section{Geostatistical approach using GIS software}

\section{IV.1. Geostatistical approach to estimate the thickness of the compressible layer at the site level}

Analysis of geotechnical data shows the strong heterogeneity of the compressible layer, so it was necessary to take into account the spatial distribution of the measured information. The geostatistical method [9]; [10]; was used to model the thickness of the compressible formation on our study area. Fig.4 gives the experimental variogram of the thicknesses of compressible soils and the theoretical model that we adjusted.

The thickness of the compressible layer is on average about sixteen meters, but it has significant variations. Thicknesses are spatially correlated to about $150 \mathrm{~m}$ away. We, therefore, adjusted to the experimental variogram a spherical model with a range of $500 \mathrm{~m}$ and a bearing of $55 \mathrm{~m}^{2}$, with a nugget effect of $0 \mathrm{~m}^{2}$.

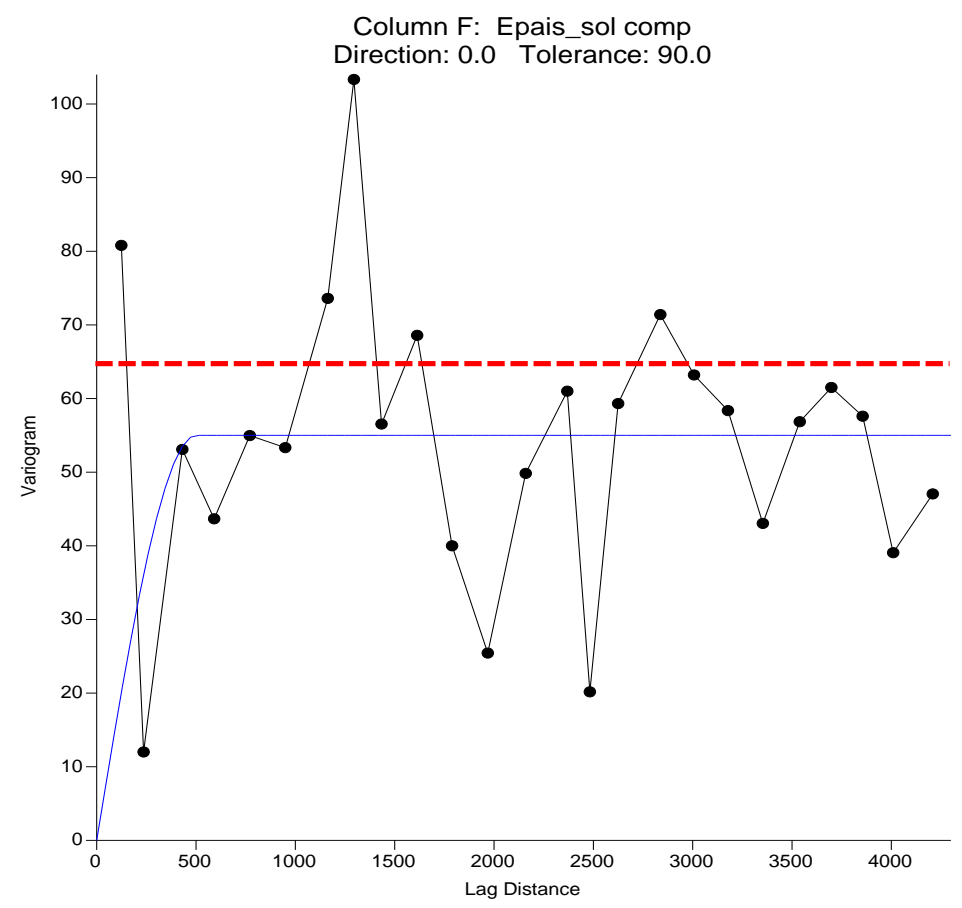

FIGURE 4. EXPERIMENTAL AND THEORETICAL VARIOGRAM ANALYSIS OF THE COMPRESSIBLE

The thickness estimation of the compressible layer is shown in Fig.5. This estimation was made using the kriging technique in inequality constraint, which allows to simulate the desired thickness at points of geotechnical surveys that have not fully crossed the soil layer while taking into account the information in theses points and the data structure surrounding. It was found that the thickness of the compressible formation is highly variable over the area. These variations can be explained by the particular geological context of the site: the presence of the Sebou Valley, resulting thicknesses of several meters per compressible place. Fig.5 (b) shows a distribution of standard deviations of kriging relatively homogeneous. We can conclude that the density of geotechnical surveys was quite satisfactory, and the information included in the kriging for inequalities was useful to reduce uncertainties in these points. 


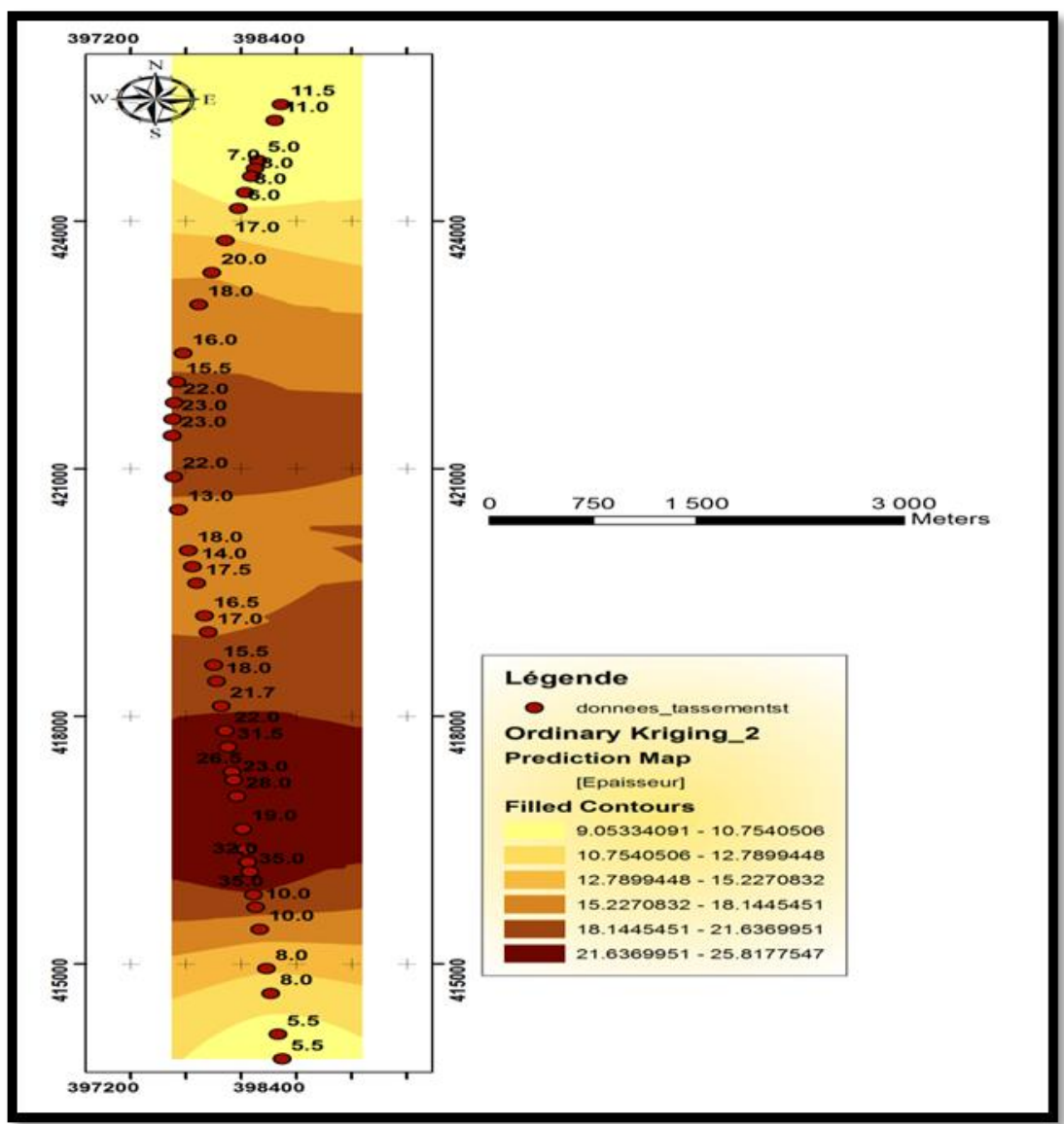

a) The interpolation of the thickness by spherical kriging model

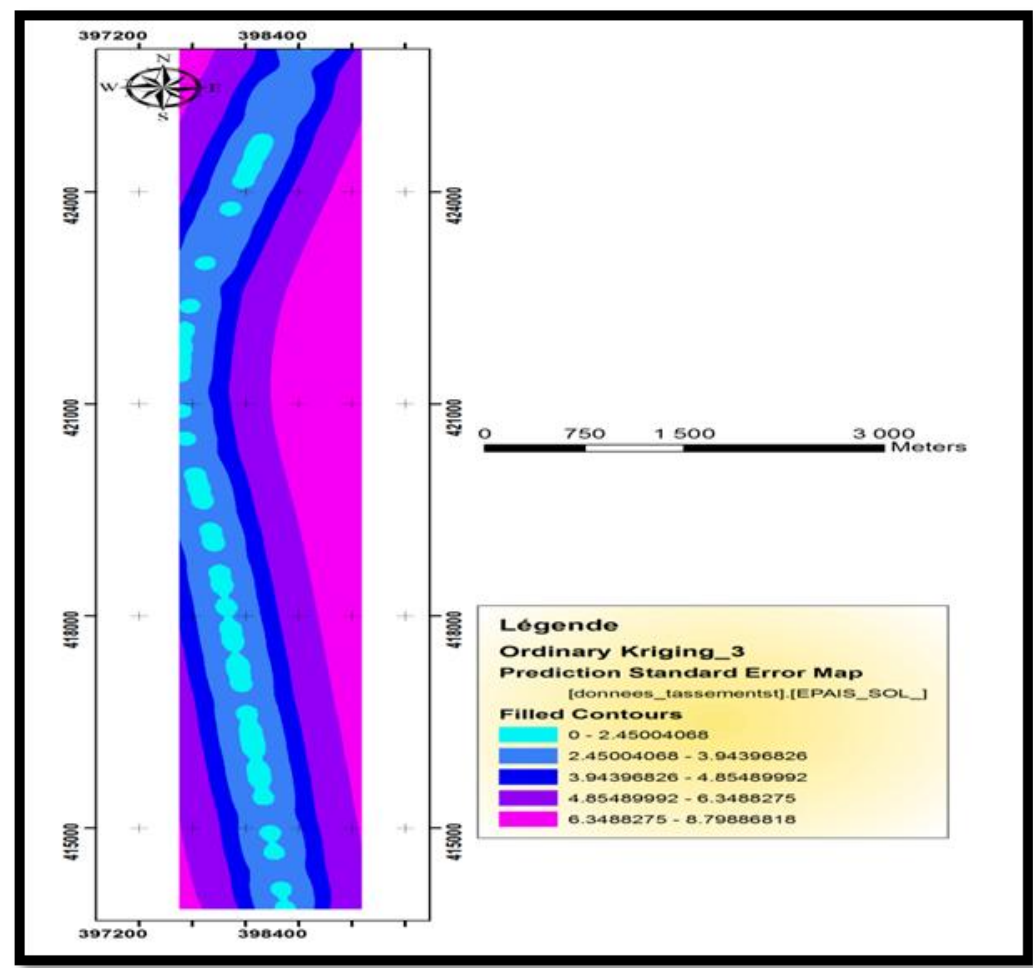

b) Standard deviation of krigeage.

FIGURE 5 . MAP OF THE COMPRESSIBLE LAYER THICKNESS ESTIMATED IN THE STUDY AREA: A) INTERPOLATION OF THE THICKNESS USING SPHERICAL KRIGING -B) KRIGING STANDARD DEVIATION. 
Using the GIS software and using the geostatistical option, enable to establish the spatial variation of the total thickness of the compressible layer using the same principle as described above.

The Map representing the spatial distribution of the compressible layer thicknesses shows a structuration of values into several zones of similar characteristics: the North and South zones, of very small thickness of the compressible area and the central portion of the site characterized by relatively large thickness.

Fig.5b shows the map of the uncertainty in the calculation of the thickness using kriging. This map shows the error on thickness estimation is low around the sampling points and it is great for remote areas.

\section{IV.2 Geostatistical approach to estimate settlement at the site level}

Fig.6 shows the modeling of the variogram of settlement with spherical and exponential models.

IV.2.1 Variogram modeling with spherical and exponential models

Settlement values are about seventy meters on average, but show significant variations. The settlements are spatially correlated to about $500 \mathrm{~m}$ away; we have in fact adjusted on the experimental variogram a composite model (spherical and exponential) whose characteristics are presented in Table 3.

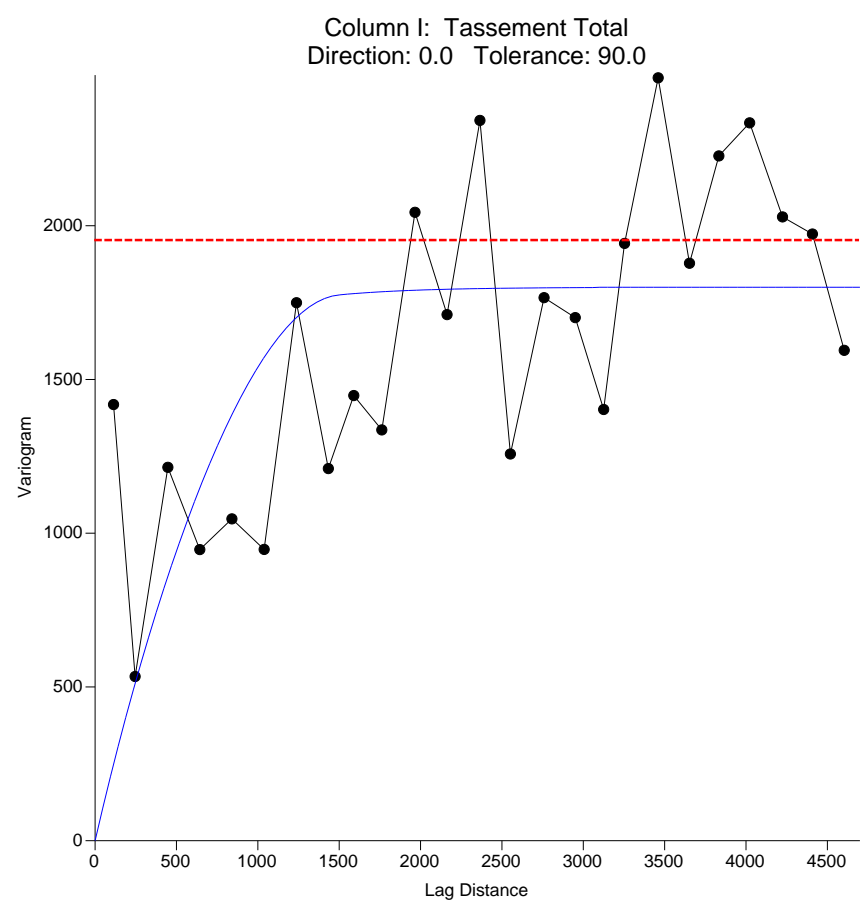

FIGURE.6. VARIOGRAM MODELING WITH SPHERICAL AND EXPONENTIAL MODELS

TABLE.3. CARACTERISTICS OF THE SPHERICAL AND EXPONENTIAL COMPOSITE MODEL

\begin{tabular}{|l|l|}
\hline \multicolumn{1}{|c|}{ Sphérique } & \multicolumn{1}{c|}{ Exponentiel } \\
\hline Effet pépite $=0 ;$ & Effet pépite $=0 ;$ \\
\hline Scale (plateau) $=500$ & Scale (plateau) $=1300$ \\
\hline Length (portée) $=500 \mathrm{~m}$ & Length $($ portée $)=1500 \mathrm{~m}$ \\
\hline
\end{tabular}

By using this variogram model, we were able to map the spatial distribution of the settlement with the use of kriging and the help of the GIS software.

Fig.7b shows the map of the uncertainty in the calculation of the settlement using kriging technique. As the thickness of the compressible area, this map shows that the error on the estimation of this parameter is low around the sampling points and it becomes great for remote areas. 


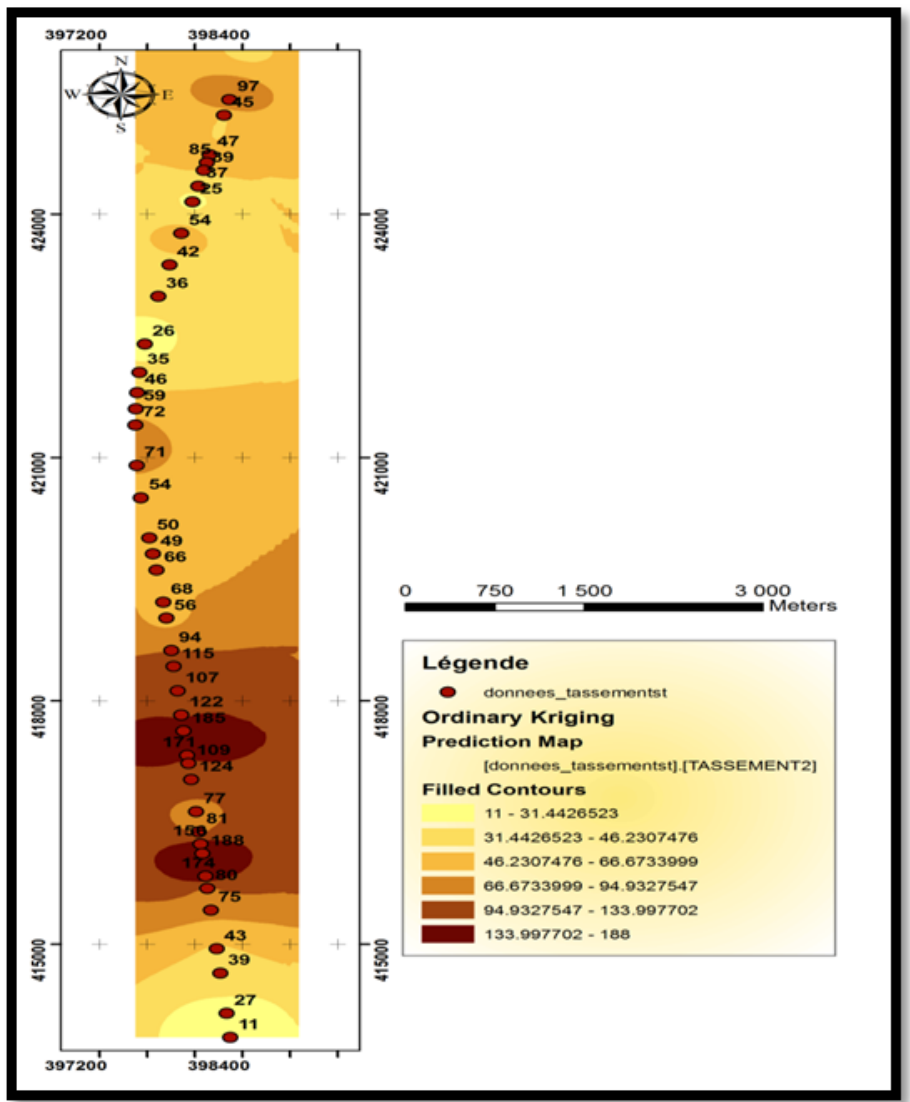

FIGURE 7.A) MAP SETTLEMENT USING KRIGING WITH SPHERICAL AND EXPONENTIAL MODEL AT THE SITE LEVEL

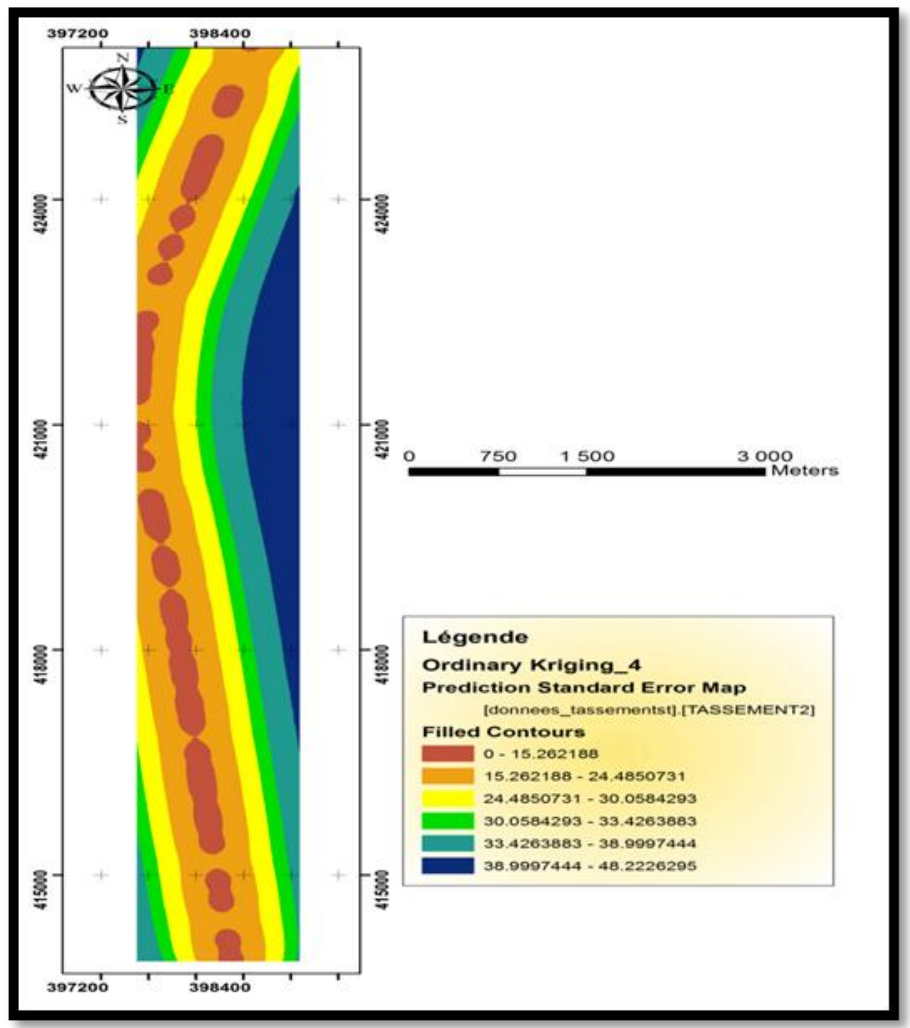

FIGURE 7: B) MAP OF THE UNCERTAINTY ABOUT THE ESTIMATION OF THE SETTLEMENT 
The total settlements were calculated using the odometer method. Their amplitude depends on the compressibility of the soil and the thickness of the various layers considered in the calculations.

To establish the longitudinal profile of earthmoving, compaction calculated values for each profile were introduced in the areas of application and adjusted depending on the height of the longitudinal profile of the final draft in addition to general overload of $1.5 \mathrm{~m}$.

The estimated settlements are generally variable on the site and are between $0.5 \mathrm{~m}$ and $2.15 \mathrm{~m}$. However, we can distinguish three families of the settlement areas:

- Areas where the total settlements are less than $0.5 \mathrm{~m}$;

- Areas where the settlements are between $0.5 \mathrm{~m}$ and $1 \mathrm{~m}$;

- Areas where the settlements exceed $1 \mathrm{~m}$ and $2.15 \mathrm{~m}$ that reached in the areas near the Sebou valley.

\section{Conclusion}

Sensible infrastructures to the settlements require detailed geotechnical study that takes into account the variability and heterogeneity of soils, often not included in the calculation of the compressibility of the site from odometer tests.

In this paper, the values of the settlements calculated were processed by a geostatistical approach that has allowed us to propose a map of the settlements across the site and a mapping of the uncertainties in the estimation of this value. Similarly, a spatialization of the thickness of the compressible area and a mapping of the probable uncertainties has been established.

\section{Acknowledgements}

We thank the Morrocan Office of railways (ONCF) for their cooperation and for providing us with the data necessary for the completion of this work.

\section{Bibliographic References}

[1] Le Coz, J., 1964. The Rharb Fellahs and settlers. Study of regional geography, frames the nature and history, 1, Rabat, Morocco, 487.

[2] Choubert, G., 1957. Test cycles correlation between marine and continental Pleistocene of Morocco. C.R. Acad.Sci. Paris, 245, 13, 1066-1069.

[3] Michard, A., 1976. Elements Moroccan geology. Notes and Mem. Serv. Geol. Morocco, 252, 408.

[4] Cirac, P., 1985. The southern basin Neogene western Rif higher. Evolution of sedimentary dynamics and paleogeography during filling phase. Thesis of Science, University of Bordeaux I, France, 283.

[5] Chalouan, A., Michard, A., 2004. The Alpine Rif Belt (Morocco): a case of mountain building in a subduction-subductiontransform fault triple junction. Pure and Applied Geophysics, 161, 489-519.

[6] Chalouan, A., Michard, A., Feinberg, H., Montigny, R., Saddiqi, O., 2001. The Rif mountain building (Morocco): a new tectonic scenario. Bull. Soc. Géol. Fr., 172, 5, 603616.

[7] Michard, A., Chalouan, A., Feinberg, H., Goffé, B., Montigny, R., 2002. How does the Alpine belt end between Spain and Morocco? Bull. Soc. Géol. Fr., 173, 1, 3-15.

[8] Platt, J. P et al 2003). The ultimate arc: Differential displacement, oroclinal bending, and vertical axis rotation in the External BeticRif arc. Tectonics, 22, 1017-1035.

[9] Matheron G., 1962. Traité de géostatistique appliquée. Mém. BRGM, 14, t.I \& II.

[10] Be Chilès J.P et Delfiner P., 1999. Geostatistic: modeling spatial uncertainty. Wiley series in Probability and statistic, Wiley, 695 p. 